\title{
Cooperative Learning and Soft Skills Training in an IT Course
}

\author{
Aimao Zhang \\ Georgia Southern University, Statesboro, GA, USA \\ aimao@georgiasouthern.edu \\ Executive Summary
}

Pedagogy of higher education is shifting from passive to active and deep learning. At the same time, the information technology (IT) industry and the Accreditation Board for Engineering and Technology (ABET) are demanding soft skills training. Thus, in designing an IT course, we devised group teaching projects where students learn to work with peers in a constructive and cooperative manner as they achieve deep learning by fulfilling their teaching responsibilities. The collective student effort provided the amount of tutoring required to cover JSP, PHP, Ajax, XML, HTML5, and RSS, which would be impossible for one instructor.

While the group project provides excellent opportunities for soft skills training and deep learning, its practical realization is difficult to assess. Group activities often take place outside of the classroom, and instructors are kept out of communication and interaction loops. This may lead to a free-rider problem where some students are awarded the same grades as others who contribute more than their fair share of the work. To address this problem, we designed and administered two peer assessment tools.

This paper reports the students' response to the course design and shares two soft skills assessment tools with IT educators in an effort to meet the demands of the IT industry and ABET. The study should prove especially valuable to those who teach in the fast advancing field of web technologies.

Keywords: soft skills, deep learning, information technology, course design, peer assessment.

\section{Introduction}

Colleges and universities are shifting from a passive learning pedagogy to active deep learning (Tagg, 2003). At the same time, the IT industry and Accreditation Board for Engineering and Technology (ABET) require IT graduates to attain soft skills, or the ability to communicate well, work in teams, and manage conflict. To meet both these demands, we designed and implemented an IT course to promote deep learning and soft skills training. Its distinguishing feature is group

Material published as part of this publication, either on-line or in print, is copyrighted by the Informing Science Institute. Permission to make digital or paper copy of part or all of these works for personal or classroom use is granted without fee provided that the copies are not made or distributed for profit or commercial advantage AND that copies 1 ) bear this notice in full and 2) give the full citation on the first page. It is permissible to abstract these works so long as credit is given. To copy in all other cases or to republish or to post on a server or to redistribute to lists requires specific permission and payment of a fee. Contact Publisher@InformingScience.org to request redistribution permission. teaching, which differs from other group studies where presentations are the final deliverable. Group teaching requires a thorough understanding of the topic and the soft skills to communicate at different levels-member-to-member in the group and group-to-class in the class.

\section{Study Objectives}

This descriptive study describes the design of an IT course and reports the 
students' response. The course is designed to meet the following objectives:

- Cover many technical skills (hard skills);

- Provide training in interpersonal skills (soft skills);

- Facilitate active and deep learning through cooperative group learning and teaching; and

- Design and administer soft skills assessment tools.

In the following sections, we discuss higher education demands and challenges, review the literature on cooperative learning and deep learning, and describe the design of a course for training future IT professionals to work effectively as a team, to take responsibility for their own learning, and to learn at a deep level in order to teach others and judge others' performance. The two assessment tools for peer evaluation are presented followed by a report on the students' response and a conclusion.

\section{Challenges and Demands}

\section{Demand for Soft Skills}

Hard skills are the technical skills required to perform a certain type of task, and soft skills are interpersonal skills, such as communication, teamwork, and conflict management (Schulz, 2008). Both the IT industry and ABET emphasize soft skills. In a recent survey, 348 IT managers were asked to rate the importance of various skills (Aasheim, Li, \& Williams, 2009). Soft skills were highly rated (see Table 1), while hard skills, such as knowledge of operating systems, hardware concepts, database, security, web development languages, telecommunications, and networking, were rated much lower.

Table 1. Top 17 Skills Ranked by 348 IT Managers

\begin{tabular}{lll}
\hline \multicolumn{1}{c}{ Skills and Traits } & Scale of 1 to 5 \\
\hline 1. Honesty/integrity & 4.62 \\
\hline 2. Communication skills & 4.54 \\
\hline 3. Analytical skills & 4.51 \\
\hline $4 . \quad$ Ability to work in teams & 4.49 \\
\hline 5. Interpersonal skills & 4.37 \\
\hline $6 . \quad$ Motivation & 4.37 \\
\hline 7. Flexibility/adaptability & 4.33 \\
\hline 8. Creative thinking & 4.18 \\
\hline $9 . \quad$ Organizational skills & 4.13 \\
\hline 10. Relevant work experience & 4.06 \\
\hline 11. Awareness of IT technology trends & 4.04 \\
\hline 12. Operating systems & 3.99 \\
\hline 13. Hardware concepts & 3.92 \\
\hline 14. Database & 3.92 \\
\hline 15. Security & 3.91 \\
\hline 16. Telecommunications/Networking & 3.90 \\
\hline 17. Web development languages & 3.85 \\
\hline Note: Original table lists 32 skills and traits. Source: Aasheim, Li, \& Williams (2009, p. 353).
\end{tabular}


ABET specified two program outcomes in its Criteria for Accrediting Computing Programs: "ability to function effectively on teams to accomplish a common goal" and "ability to communicate effectively with a range of audiences” (2010, p. 3). The concept of soft skills is not new to higher education; accrediting agencies have recommended them for over a half-century (American Society for Engineering Education, 1950). However, soft skills training is still particularly weak in science and engineering programs (Schulz, 2008) and hampers the career progression of today's IT graduates (Williams, 2011). Like engineering programs, IT curricula are loaded with hard skills courses, and adding another soft skills course is almost impossible. Thus, one of the objectives of this study was to embed the soft skills training in a hard skills course.

\section{Demand for Active and Deep Learning}

Pedagogical approaches can be classified as passive or active. In passive learning, students merely receive; the instructor designs the learning program, determines assessment criteria, delivers lectures, and evaluates student performance (Falchikov, 1986). In active learning, students participate in, or take full responsibility for, learning.

Learning can also be categorized as surface or deep (Tagg, 2003). Surface learning focuses on information and emphasizes repetition and memorization techniques. According to Tagg (2003, p. 70), "Deep learning is learning that takes root in our apparatus of understanding, in the embedded meanings that define us and that we use to define the world."

Colleges and universities are shifting from a passive learning pedagogy to active and deep learning pedagogy, but some fields are shifting at a slower pace than others. Compared with other fields, engineering practices less deep learning (Nelson Laird, Shoup, \& Kuh, 2005). Figure 1 compares disciplines in terms of their use of deep learning approaches. Thus, one objective of our course design was to promote active and deep learning in IT education.

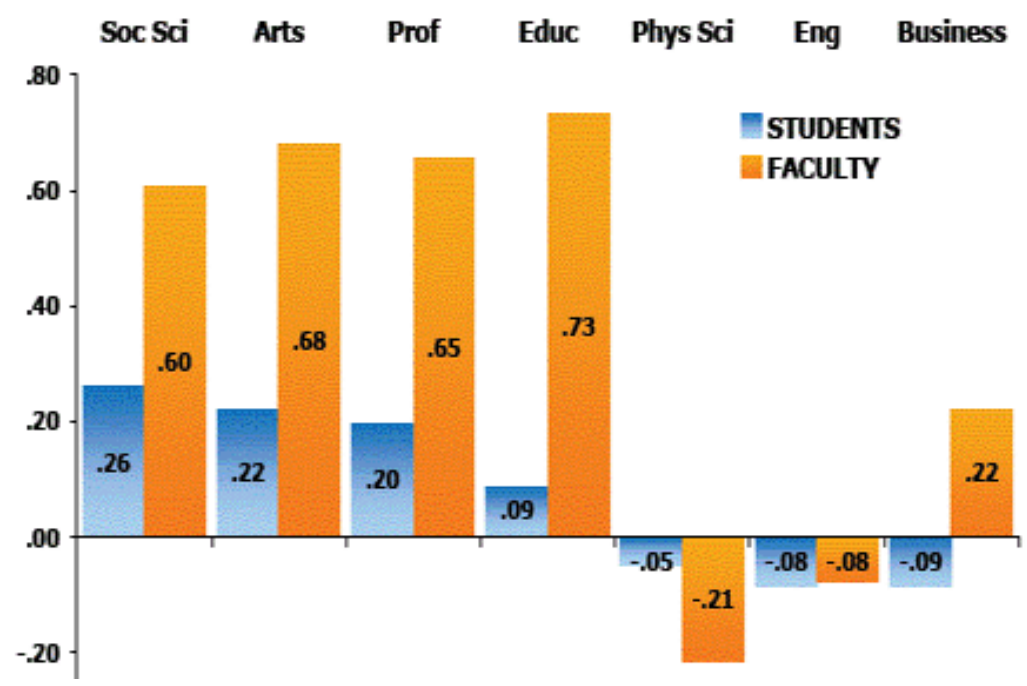

Figure 1. Disciplinary Comparisons of Standardized Means of Deep Learning Approaches. Source: Kuh, Laird, \& Kinzie (2006)

\section{Challenges in Assessing Soft Skills}

Assessment is defined as the activities and processes involved in judging performance (ReeseDurham, 2005). Since Skinner's study of human behavior (1953), hundreds of studies have established that human behavior is shaped by intrinsic motivation and extrinsic rewards, which positively influence intrinsic motivation (Deci, Koestner, \& Ryan, 1999). The performance assess- 
ment is an extrinsic reward that has enormous influence over what and how students learn (Gibbs \& Haveshaw, 1989).

In traditional pedagogy, tests and assignments are used to assess individual student performance. Students have little input on the assessment criteria and process (Falchikov, 1986). However, soft skills, such as interpersonal and leadership skills, cannot be accurately measured by quizzes or exams. While the group project provides excellent opportunities for soft skills training, its practical realization is difficult to assess. Group activities often take place outside of the classroom, and instructors are kept out of communication and interaction loops. This may lead to a free-rider problem where some students are awarded the same grades as others who contribute more than their fair share of the work.

A tremendous amount of effort has been invested in specifying protocols and designing standardized assessment tools to measure interpersonal communication skills of doctors, counselors, and nurses (Accreditation Council for Graduate Medical Education, 2005). The importance of interpersonal skills between doctor and patient during the diagnostic process or among a surgical team during an operation is easy to appreciate. However, less effort has been invested in developing assessment tools to measure the soft skills of future IT professionals, who need soft skills to optimize teamwork and effective relations with clients. This study is an initial effort to explore the design soft skills assessment tools for IT education (see the Appendix).

\section{Challenges of Teaching Web Technology}

The course designed in this study teaches web application design and development. New web technologies and new versions of web technologies are released continuously. There are numerous competing as well as complementary web technologies. There is no standard way to design and implement a web site, and there is no guarantee that what students learn today will not be obsolete by the time they graduate. IT graduates are expected to apply existing knowledge and to learn new skills in the workplace (Aubert, 1991). Thus, one objective of our course design was to teach several web technologies and to train students to gain mastery on their own.

\section{Literature Review}

Cooperative learning is defined as a learning atmosphere that focuses on group identification and working with peers in a constructive manner (Johnson \& Johnson, 1994) and that fosters discovery and exploration (Lejk \& Wyvill, 2001). Group projects are more effective in deep learning than other methods, such as essay tests or multiple choice tests (Figure 2). Students engaged in deep learning have higher levels of intellectual development and satisfaction with higher education (Nelson Laird et al., 2005). Numerous studies support the deep learning advantages of group projects, for instance, poster presentations on the use of the biosciences to solve industrial problems (Butcher \& Stefani, 1995), group presentations in pharmacology (Hughes \& Large,1993), case studies in production management (Kaimann, 1974), simulated training for groups in hotel management and tourism (Kwan \& Leung, 1996), team presentations in American history and literature (Oitzinger \& Kallgren, 2004), and team learning in business and organizational communication (Roebuck, 1998). 


\section{Very effective $\quad \square$ Fairly effective}

Supervised/evaluated internship/community-based project where students apply college learning in real-world setting

$69 \%$

Advanced comprehensive senior project, such as thesis, demonstrating student's depth of knowledge in major \& problem-solving, writing, and analytic reasoning skills

\section{$46 \%$}

$79 \%$

Essay tests to evaluate level of problem-solving, writing, and analytical-thinking skills

\section{$35 \%$} $60 \%$

Electronic portfolio of student's college work, including accomplishments in key skill areas and faculty assessments

$33 \%$ $56 \%$

Multiple-choice tests of general content knowledge

$7 \%$ $32 \%$

Figure 2. Effectiveness of Deep Learning through Group Projects.

Source: Association of American Colleges and Universities, www.aacu.org/meetings/effective_educational_practices/documents/CS6.ppt.

\section{Theoretical Foundations of the Course Design}

Our course design is based on two theories, cooperative learning and deep learning. Cooperative learning is an approach that turns learning activities into group social learning experiences. Students work in groups to complete tasks collectively. The teacher's role changes from giving information to facilitating students' learning.

"Deep learning is learning that takes root in our apparatus of understanding, in the embedded meanings that define us and that we use to define the world” (Tagg, 2003, p. 70). It is concerned with extracting principles and underlying meanings, making sense of facts and feelings, and integrating them with previously acquired knowledge. Rather than focus on memorization, it aims to provide greater understanding of a subject. Incorporating both theories, this course uses group projects to provide soft skills training and uses group teaching to achieve deep learning (Figure $3)$.

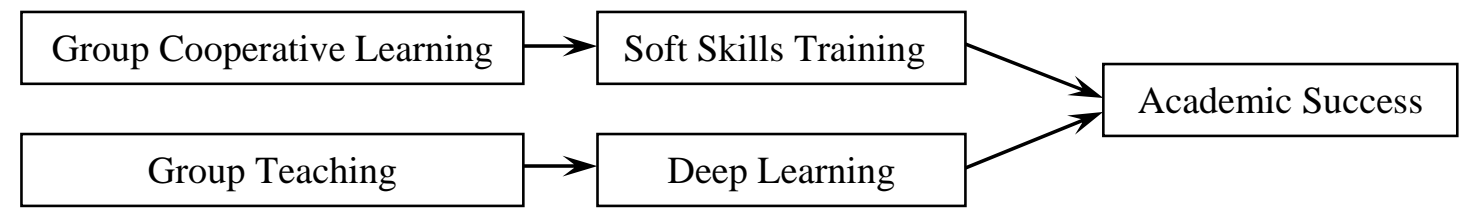

Figure 3. Incorporating Both Theories into the Course Design

\section{Course Design}

\section{Topics and Groups}

The IT course is a senior-level course which met 3.5 hours per week for a 16-week semester (see Table 2 for schedule). To keep the content relevant to new web technologies, the course covered 6 topics: 
1. JSP: JavaServer Pages is a server-side scripting language embedded into an HTML source document. It interacts with a database to produce dynamic web pages. It is translated by a JSP container on a web server.

2. PHP: Hypertext Preprocessor is a server-side scripting language embedded into an HTML source document. It interacts with a database to produce dynamic web pages. It is interpreted by a PHP processor on a web server.

3. Ajax: Asynchronous JavaScript and XML are interrelated web development methods used on the client-side to send and retrieve data from a server asynchronously in the background without interfering with the display of the existing page.

4. XML: Extensible Markup Language defines a set of rules for encoding documents in a format that is both human- and machine-readable. In this course, XML is used as data source to replace fancy databases.

5. HTML5: The fifth revision of HTML (HyperText Markup Language) for structuring and presenting content on web pages is still under development as of March 2012.

6. RSS: Really Simple Syndication is a family of web-feed formats used to publish frequently updated works, such as blog entries, news headlines, audio, and video, in a standardized format.

Except for HTML5, all these topics involve server-side programming. The basic features of HTML5 are taught in a client-side programming course, while this course covers its local storage features. The topics are expected to change each semester to reflect changes in the IT industry.

Students were randomly assigned to teach PHP, Ajax, XML, HTML5, or RSS. The instructor taught JSP and assisted the student groups in learning and teaching the other 5 topics. Prerequisite classes covered HTML, CSS, JavaScript, Java, database management, and server configuration. The class had 24 students, 5 women, 19 men, ranging in age from 20 to 31, majoring in IT or preIT: Their total credit hours earned ranged from 43 to 168.

Table 2. Class Schedule

\begin{tabular}{|c|c|c|}
\hline Date & Topics & Activities \\
\hline 3.5 week & JSP & Instructor teaches JSP with individual assignments \\
\hline 2.5 week & $\begin{array}{l}\text { Group } \\
\text { learning }\end{array}$ & $\begin{array}{l}\text { - Textbook (Sebesta, 2010) } \\
\text { - Each group receives a set of program codes and a brief } \\
\text { assignment instruction from the instructor } \\
\text { - Group prepares PPT presentation, assignment } \\
\text { instructions, test questions, and suggested reading } \\
\text { materials } \\
\text { - Collect first-round peer evaluations within all groups }\end{array}$ \\
\hline 1.5 week & PHP & \multirow{5}{*}{$\begin{array}{l}\text { - Each group gives lectures and tours labs } \\
\text { - Each student has a project assignment, a written test, } \\
\text { and an online quiz } \\
\text { - Each group is evaluated by the class } \\
\text { - Collect second-round peer evaluations within all } \\
\text { groups }\end{array}$} \\
\hline 1.5 week & Ajax & \\
\hline 1.5 week & XML & \\
\hline 1.5 week & HTML5 & \\
\hline 1.5 week & RSS & \\
\hline Final & & Term Paper on Group Teaching \\
\hline
\end{tabular}




\section{Facilitating Phase}

Renkl, Atkinson, Maier, and Staley (2002) reviewed various active learning methodologies and suggested that the best approach is to give students guidance at the beginning and then let them practice on their own. Following this suggestion, the course instructor taught JSP for the first 3.5 weeks and prepared the students to learn PHP, Ajax, XML, HTML5, and RSS on their own. Students completed a JSP assignment: an E-Commerce application that enabled internet customers to search product information stored in a database and add products to a shopping cart. JSP and PHP have similar characteristics. This facilitating phase lowered the learning curve for PHP and other topics and established a good example of teaching for students to follow.

\section{Cooperative Group Learning}

During the next 2.5 weeks, the five groups worked separately. First, they all negotiated contracts that included task assignments, methods of communication, and conflict resolution. Each group then learned and prepared to teach its topic to the rest of the class. For each topic, the instructor provided a set of written program codes and a brief assignment instruction. The group was responsible for figuring out the codes and designing detailed assignment instructions. No lectures were given during the group learning period. The groups learned by analyzing the code, reading the textbook, and searching for and reading materials online. During this period, they submitted drafts of a PPT presentation, assignment instructions, test questions, and suggested reading materials to the instructor for feedback. Final drafts of each item were resubmitted at the end of the period.

\section{Group Teaching and Delivering}

After the 2.5 weeks of preparation, all teams were ready. The PHP group taught first for several reasons. First, PHP is the foundation for other topics. Second, it is similar to JSP, which the instructor introduced to the class. Third, the PHP assignment is identical to the JSP assignment except that it is implemented in PHP, so the class was able to accelerate into the PHP environment smoothly. The Ajax group was scheduled immediately after the PHP group. Like JSP and PHP, Ajax uses a 3-tier architecture consisting of client, server, and database. The rest of the groups can follow in any order. Each group had 1.5 weeks to present a topic, run the labs, tutor students, and grade assignments and tests. The instructor provided only guidance and double checked the grading of tests and assignments. Table 3 summarizes the course's combination design.

Table 3. Combining Individual and Group Learning

\begin{tabular}{lll}
\hline & Individual & Group \\
\hline Skills & $\begin{array}{l}\text { Hard skills: web design } \\
\text { technology }\end{array}$ & $\begin{array}{l}\text { Hard skills: web design technology } \\
\text { Soft skills: communication, cooperation, } \\
\text { conflict resolution, leadership, } \\
\text { responsibility, organization }\end{array}$ \\
\hline Assessment tools & $\begin{array}{l}\text { Quizzes, tests, } \\
\text { assignments }\end{array}$ & $\begin{array}{l}\text { Group peer evaluation } \\
\text { Class peer evaluation }\end{array}$ \\
\hline Deep learning & Create web applications & $\begin{array}{l}\text { Learn in order to teach others and judge } \\
\text { others' performance }\end{array}$ \\
\hline Setting & $\begin{array}{l}\text { In-classroom learning } \\
\text { taught by groups instead } \\
\text { of an instructor }\end{array}$ & $\begin{array}{l}\text { Outside classroom group learning and in- } \\
\text { classroom teaching and tutoring }\end{array}$ \\
\hline
\end{tabular}




\section{Design and Administration of Assessment Tools}

We designed and administered assessment tools to evaluate soft skills. The assessment tools were designed to influence students' behavior and motivate them to develop soft skills. The assessment tools were presented to the class at the beginning of the semester, so that students would have a clear understanding of the evaluation criteria and who would evaluate them. This preparation motivates students to improve their skills in communication, cooperation, conflict resolution, and organization. The assessment also provided an incentive for students to learn deeply and teach effectively.

After reviewing the existing assessment tools (Gueldenzoph \& May, 2002; Levi \& Cadiz, 1998), we designed two instruments to measure soft skills (see Appendix). Group peer evaluation has 18 items and is designed for group members to evaluate each other. Class peer evaluation has 14 items and is used by the class to evaluate the groups' performance. Two group peer evaluations were administered, the first at the end of group learning and the second at the end of the group teaching. The one class peer evaluation was administered at the end of group teaching. We created the assessment tools using online survey software and questionnaire tools at surveymonkey.com. A hyperlink was provided on a Blackboard Learning System, where other course materials were posted. The data are automatically collected at surveymonkey.com.

\section{Lab Configurations}

Several factors were considered in preparing a lab for this course: minimal IT support and maintenance, minimal software cost for the university, convenience and availability to students, and popular competing and complementary software. All software (Table 4) could be downloaded for free from the Internet. LAMP (Linux, Apache, MySQL, and PHP) was selected because it is a popular software configuration for a web server. Opera was selected because it supported HTML5 at the time. The course introduced two web servers: Apache and Apache Tomcat, which are competing technologies. They were configured into one virtual machine and installed on lab PCs. A virtual machine is easy to maintain and creates less conflict for lab PCs, which are configured for many other IT and computer science courses. The virtual machine also provides an opportunity for students to tinker with configuration and settings. Students could copy the virtual machine from a lab PC onto their portable hard drives for use outside class, so they did not have to depend on the availability of computer labs.

Table 4. Software Development Environments

\begin{tabular}{lcc}
\hline \multicolumn{1}{c}{ Components } & Environment 1 & Environment 2 \\
\hline Operating system & Ubuntu (Linux based) \\
\hline Server & Apache Tomcat & Apache PHP \\
\hline Database & \multicolumn{2}{c}{ MySQL } \\
\hline Web front-end tool for Database & phpMyAdmin \\
\hline Editors & \multicolumn{2}{c}{ geditor } \\
\hline Browser & Opera \\
\hline
\end{tabular}

\section{Discussion}

The last course assignment was a term paper, which required students to review the group teaching experience, to discuss positive and negative experiences, and to tell a story about their groups. Out of 24 students, 23 submitted their term papers. Their responses are reported below. 


\section{Learned Technical Skills (Hard Skills)}

Thanks to the collective effort of the students, the course covered several topics (JSP, PHP, Ajax, XML, HTML5, and RSS). The class as a whole was able to divide and conquer, and to learn more; one instructor could not teach and provide the amount of tutoring that the groups were able to provide.

Student No. 7 wrote, "First and foremost, I felt as though every language discussed was VERY current, and a graduating IT or CS major could likely get a job using any of these languages we covered."

Student No. 13 wrote, "It definitely helped me, as a non-web application emphasis, to be able to learn such a variety of topics through the course of the semester."

Student No. 14 wrote, "For instance, by dividing the class into groups and having them teach a myriad of techniques, rather than having a professor teach all semester . . . students can learn not only their own assigned topics, but others as well. I do believe group work was one of the most effective ways to rapidly cover a plethora of topics during this semester.”

\section{Gained Interpersonal Skills (Soft Skills)}

Cooperative group learning provides the environment and interactions necessary to learn soft skills (Lejk \& Wyvill, 2001). Learning with a group rather than from an instructor requires trust, sharing, and conflict resolution. To act as a team, group members had to learn how to respect and listen to others. Through the process, they built bonds and made friends. Group communication and interaction took place at two levels: member-to-member and members to class. Students learned to communicate on a larger scale when they made presentations and tutored the class. The success of a group project largely depends on organization, cooperation, and communication skills. Nineteen out of 23 students specifically stated that the group projects were valuable to them. They gained interpersonal skills and opened themselves to others.

Student No. 4, a member of the PHP group that delivered the best job according to the class peer evaluation, wrote:

The social interaction extended even outside of our individual groups, especially while working on the assignments; when helping others with our group's assignments or getting help from members of other groups while working on their assignment. We were all brought together with a common goal and feeling of accomplishment when the assignment was completed.

While I was 'titled' as the leader, Kevin was our actual group leader - and a damn good one at that. Kevin truly was the glue that held the rest of us together. Brandon had the knowledge base that we could rely on, and Ronald was the workhorse that never questioned what the group asked of him. It really was a great bunch of guys to work with.

Conflicts taught students to learn from mistakes and to admit wrong in front of others. Student No. 12 wrote, "I was notified of my embarrassment where I lashed out at the group members. This led me to have a heated mail discussion with them and place strain on the relationship keeping the group together. In the end I realized my errors and apologized, causing things now to only be slightly awkward, but endurable."

\section{Achieved Deep Learning}

Students have to understand a topic thoroughly in order to teach it. Each group member was expected to answer questions and help other students with assignments during lab hours. In many 
previous group studies, a class presentation is the final deliverable; in this study, the group project's goal was to teach and help others to learn.

Grading others' work is a form of deeper learning (Fry, 1990). By designing quiz and test questions and grading tests and assignments, students have another opportunity to gain a deeper understanding of the topic.

Student No. 1 wrote, "I learned PHP the best out of all the topics because when I was helping people who asked questions about the assignments trying to explain it to them helped me to understand and grasp concepts about PHP that I wouldn't have figured out otherwise.”

Student No. 7 wrote, "The first positive point of the teaching experience is that I was forced to self-teach myself, which is a very useful tool in IT."

Student No. 8 wrote, "By us having to teach our peers this meant that we had to thoroughly know the coding language - otherwise our peers would not be able to learn from us.”

Student No. 17 wrote, "They say that someone who teaches a subject will actually retain $80 \%$ of that information without much effort. The benefit of group teaching is just that."

Student No. 20 wrote, "I think I may have had the best experience in a group project atmosphere than just about any other group I have been in during my college career. I feel like the way this class was presented was the best possible way for me to learn and I certainly learned a lot. I believe having the students present each topic area offered a fresh and relatable way to learn each technology."

\section{Students as Powerful Resources}

This course leveraged students into a valuable teaching force.

Student No. 1 wrote, "All of the groups and their members were friendly and offered assistance when needed and did their best to explain everything so that it was not hard to understand."

Student No. 2 wrote, "Since there were usually four or five students to run the lab, there was plenty of help to go around if you needed it."

Student No. 22 wrote, “I’ve learned a lot from this group of peers. I felt as if they were really knowledgeable of their topic and I believe that is what made it more interesting. My positive experiences were great. It seemed to me like they were really teachers up there in front of the class. They were speaking clearly, made eye contact and answered questions and gave assistance.”

\section{Increased Participation and Attendance}

During my 10 years' teaching experience, I had never had a better attendance than this class. The level of excitement, commitment, and involvement was unprecedented.

Student No. 6 wrote, "It was a nice change of pace from the usual, sitting in class and listening to the professor lecture for the entire period."

Student No. 11 wrote, "As someone who experienced the class both the previous semester and this one - I absolutely prefer the group teaching. It kept me involved at a greater level of contribution, and I understood the material at a much greater rate. Overall, I absolutely loved coming to class.”

Student No. 16 wrote, “As far as group teaching goes, I think it's a swell idea for students. It makes things less difficult and actually more fun. A lot of the time, students do not learn because we are bored to death. We are just thinking about class ending and what to do afterwards, truthfully. But peers teaching and learning from peers is exciting instead of listening to one professor 
the entire semester, and even more exciting because it's not the same peers that are teaching, so it actually gives students something to look forward to, I think. Group teaching as a whole is a great experience! We learn patience to deal with others and build our confidence in public speaking as well. Some professors should really look into it instead of boring us to death.”

\section{Shortcomings}

As expected, students expressed some concerns in their term papers: too many topics in too little time, lack of teaching experience and poor quality, difficulties in scheduling group meetings outside class, and slackers.

\section{Too many topics and too little time}

Student No. 4 wrote, "I don't feel 3 days is quite enough to complete many of the assignments in class. The assignments were usually divided into 3 sections and each section was checked off each day, but if the test or presentation took too long we would not have enough time to finish one section each day. There were a couple days I stayed late after class, skipping my class at 5PM to finish the assignment to get checked off. Another issue is retention. I'm not sure if it is the time constraints, the number of languages we were trying to learn, or more likely both, but I feel that may impact the ability to retain the information.”

\section{Lack of teaching experience and poor quality}

Student No. 6 wrote, "We had a limited time to teach ourselves the material before presenting it to the class. Not fully knowing the material ourselves made it harder to teach the rest of the class."

Student No. 15 wrote, "I do not feel that some of the other languages were taught very well, especially the XML group. I feel that they were not very aware of what was going on, or if they did, they did not know how to convey the thought process behind it.”

Student No. 17 wrote, “There were a couple groups that presented their information, but still seemed to be lacking information which forced me to find it myself. I have no problem with this, but everyone learns differently. This brings me to my next point. Some people are just bad at teaching. It has nothing to do with how well they got the information. It is about how well they are able to present the information. Some people tend to forget that you're teaching to people that have most likely never seen it before.”

\section{Difficulties in scheduling group meetings outside class}

Student No. 22 wrote, "Many of us could not meet outside of our classes due to the fact that jobs played a big role in deciding where, when and how to meet. I know that I had to work in another county with shifts ending at 9:30 and the trip was at least 45 minutes away.”

Student No. 14 wrote, "I noticed that there was a major conflict with our ability to meet as a group. Several members had children that required their constant attention.”

\section{Slackers}

Student No. 15 wrote, "My group really did not put forth the effort as a whole. Especially one guy, he pretty much just took a backseat to the entire course. He never attended the meetings, or class for that matter."

Student No. 10 wrote, "I understand that some people have to work and there are going to be time conflicts, but every week no matter which day or time, these group members that I am referring to 
would skip the meeting. This led to me and one other group member that were meeting every week to get the work done.”

\section{Conclusion}

One of the indicators of quality in higher education is the extent to which active deep learning is nurtured. One way to achieve deep learning is to teach a topic and to judge the quality of one's own work and that of others objectively. Learning is especially important for IT professionals due to the changing nature of the field. By graduation, IT students must attain "the recognition of the need for and an ability to engage in continuing professional development” (ABET, 2010).

ABET criteria also require IT graduates to effectively integrate IT-based solutions into the user environment. According to the Robbins-Gioia Survey, 51 percent of companies that implemented ERP considered the implementation unsuccessful ("Failure Rate", 2001). User resistance to change during the deployment stage is a bigger hurdle than designing a system. Conflicts are inevitable when a computer system like ERP must be integrated across functions or divisions. IT education must prepare future IT professionals with hard and soft skills to communicate with end users, to resolve conflicts, and to bring different functions together to work toward the common goal.

This study should prove valuable for educators to promote soft-skill training and to use peer evaluations to achieve success in IT education. IT educators may use this course as an example in designing group projects for students to achieve deep learning and soft skill competency.

\section{References}

Aasheim, C., Li, L., \& Williams, S. (2009). Knowledge and skill requirements for entry-level information technology workers: A comparison of industry and academia. Journal of Information Systems Education, 20(3), 349-56.

ABET. (2010). Criteria for accrediting computing programs. Retrieved from http://www.abet.org/Linked\%20Documents-UPDATE/Program\%20Docs/abet-cac-criteria-20112012.pdf.

Accreditation Council for Graduate Medical Education. (2005). Advancing education in interpersonal and communication skills: An educational resource from the ACGME outcome project. Retrieved from http://www.acgme.org/outcome/implement/interpercomskills.pdf.

American Society for Engineering Education. (1950). Speaking can be easy for engineers, too: A concise practical approach to better public speaking and to better meetings. Prepared through the joint efforts of men in industry, education and professional engineering, many of whom are members of the Relations with Industry Division, New York.

Aubert, E. (1991). Survey shows secondary school standards are the biggest concern of universities and business. Campus, 1, 1-3.

Butcher, A., \& Stefani, L. (1995). Analysis of peer-, self- and staff-assessment in group project work. Assessment in Education: Principles, Policy \& Practice, 2(2), 165-85.

Deci, E. L., Koestner, R., \& Ryan, R. M. (1999). A meta-analytic review of experiments examining the effects of extrinsic rewards on intrinsic motivation. Psychological Bulletin, 125(6), 627-68.

Failure Rate. Statistics over IT Failure Rate. (2001). IT Cortex. Retrieved from http://www.itcortex.com/Stat_Failure_Rate.htm

Falchikov, N. (1986). Product comparisons and process benefits of collaborative peer group and self assessments. Assessment and Evaluation in Higher Education, 11(2), 146-66.

Fry, S. (1990). Implementation and evaluation of peer marking in higher education. Assessment and Evaluation in Higher Education, 15(3), 177-89. 
Gibbs, G., \& Habeshaw, T. (1989). Preparing to teach. Bristol: Technical and Educational Services, Ltd.

Gueldenzoph, L. E., \& May, G. L. (2002). Collaborative peer evaluation: Best practices for group member assessments. Business Communication Quarterly, 65(1), 9-20.

Hughes, I. E., \& Large, B. J. (1993). Staff and peer-group assessment of oral communication skills. Studies in Higher Education, 18(3), 379-85.

Johnson, D., \& Johnson, R. (1994). Learning together and alone: Cooperative, competitive, and individualistic learning. Needham Heights, MA: Prentice-Hall.

Kaimann, R. (1974). The coincidence of student evaluation by professor and peer group using rank correlation. Journal of Educational Research, 68(4), 152-153.

Kuh G., Laird, T., \& Kinzie, J. (2006). Deep learning, liberal education, and institutional practice: Emerging findings, provocative lessons. Presentation at the annual meeting of the Association of American Colleges and Universities, Washington, DC. Retrieved from http://nsse.iub.edu/pdf/conference_presentations/2006/AACU2006DeepLearning_FINAL.pdf.

Kwan, K., \& Leung, R. (1996). Tutor versus peer group assessment of student performance in a simulation training exercise. Assessment \& Evaluation in Higher Education, 21(3), 205-14.

Lejk, M., \& Wyvill, M. (2001). Peer assessment of contributions to a group project: A comparison of holistic and category-based approaches. Assessment \& Evaluation in Higher Education, 26(1), 61-72.

Levi, D. \& Cadiz, D. (1998) Evaluating team work on student projects: The use of behaviourally anchored scales to evaluate student performance. ERIC Document Reproduction Service, ED424250.

Nelson Laird, T. F., Shoup, R., \& Kuh, G. D. (2005). Measuring deep approaches to learning using the National Survey of Student Engagement. Presented at the annual meeting of the Association for Institutional Research, Chicago, IL. Retrieved from http://nsse.iub.edu/pdf/conference_presentations/2006/AIR2006DeepLearningFINAL.pdf

Oitzinger, J., \& Kallgren, D. (2004). Integrating modern times through student team presentations. College Teaching, 52(2), 64-68.

Reese-Durham, N. (2005). Peer evaluation as an active learning technique. Journal of Instructional Psychology, 32(4), 338-43.

Renkl, A., Atkinson, R. K., Maier, U. H., \& Staley, R. (2002). From example study to problem solving: Smooth transitions help learning. Journal of Experimental Education, 70(4), 293-315.

Roebuck, D. (1998). Using team learning in business and organizational communication classes. Business Communication Quarterly, 61(3), 35-49.

Schulz, B. (2008). The importance of soft skills: Education beyond academic knowledge. Journal of Language \& Communication, 2(1), 146-154.

Sebesta, R. (2011). Programming the World Wide Web (6 ${ }^{\text {th }}$ ed.). New York: Addison-Wesley.

Skinner, B. F. (1953). Science and human behavior. New York: Macmillan.

Tagg, J. (2003). The learning paradigm college. Bolton, MA: Anker Publishing Company.

Williams, J. (2011). Lack of soft skills training is curbing IT career progression. Computer Weekly. Retrieved from http://www.computerweekly.com/Articles/2011/08/26/247728/Lack-of-soft-skillstraining-is-curbing-IT-career-progression.htm 


\section{Appendix}

\section{Class Peer Evaluation}

A group is evaluated by the class. Items 1 through 13 use a Likert scale of Very Poor, Poor, Neutral, Good, or Excellent.

1. Quality of Reading and Study Materials

2. Assignment Design and Instructions

3. Content and Clarity of PowerPoint Slides

4. Delivery of Lecture and Presentation

5. Quality and Effectiveness of Lab Operation

6. Design of Quiz Questions and Short Answer Questions

7. How well did you learn from this group?

8. Overall Evaluation of This Group

9. Overall Evaluation of Member 1 (member's name)

10. Overall Evaluation of Member 2 (member's name)

11. Overall Evaluation of Member 3 (member's name)

12. Overall Evaluation of Member 4 (member's name)

13. Overall Evaluation of Member 5 (member's name)

14. Distribute a total of 100 points among the following group members.

Member 1 Member 2

Member 3

Member 4

Member 5

\section{Group Peer Evaluation}

Within a group, each member evaluates other group members, including self. Items 1 through 16 use a Likert scale of Strongly Disagree, Disagree, Neutral, Agree, Strongly Agree.

1. Attends meetings

2. Comes to group meetings prepared

3. Does quality work

4. Has quality ideas and initiatives

5. Does more than fair share of work

6. Devotes time and effort to group project

7. Completes work on time

8. Understands concept and has the knowledge of the project

9. Dependable and responsible

10. Communicates with group members

11. Cooperates and supports group members (shares resource, ideas, encouragement, constructive feedback)

12. Works through conflicts and handles conflicts in a constructive manner

13. Respectful of others' ideas and stays positive and open-minded

14. Commits to group goal

15. Takes a leadership role

16. Organizes group and helps the group to function as a team

17. At this point, what grade would you give to this group member for the project?

A

B $\quad C$

18. Distribute a total of 100 points among your group members, including yourself. Member 2
Member 4 


\section{Biography}

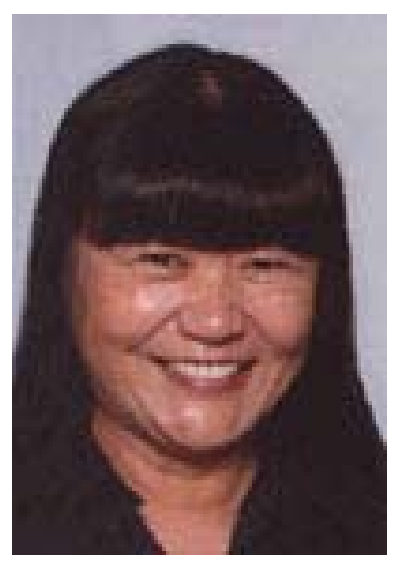

Aimao Zhang is an associate professor of Information Technology at Georgia Southern University. She received her PHD in Management Information Systems from Southern Illinois University at Carbondale. Her teaching specialties are in server-side programming, web application design and development. Her research interests include IT education, e-commerce, industrial economics, business ethics, banking and finance studies. 